\title{
HOW DOES SOCIAL CAPITAL INFLUENCE AN ONLINE SOCIAL NETWORK SYSTEM
}

\author{
LinwuGu, lgu@iup.edu, Indiana University of Pennsylvania \\ JianfengWang,jwang@iup.edu, Indiana University of Pennsylvania
}

\begin{abstract}
Although online social networks have been becoming a prominent communications tool and growing rapidly in recent years, there is a surfeit of research literature about social networks. However, there has been little research on how social capital factors impact the users' satisfaction in online social networks. Drawing on this approach, in what follows we lay out our hypotheses that the social capital resources are instrumental in explaining the user perceptions of online social networks. We therefore propose and test a model that measure the users' perceived usefulness and satisfaction perspectives by examining the influence of these factors in an empirical survey.
\end{abstract}

Keywords: Social capital (SC), online social networks (OSN).

\section{INTRODUCTION}

The Online social network system (OSN) is a network platform for users to communicate, interact, and share knowledge online. Informational social influence and factors are especially important to users' perceptions on online social network information system [4]. Social capital has been conceptualized as assets in the networks of relationships between individuals, communities, or networks [21]. Prior studies in social capital theories indicate that networks of relationships create a valuable resource for the deportment of behaviors, providing their members with structural, relational, and cognitive resources [22]. The social capital resources are available through users' contacts or connections social networks bring [23].

Based on the prior literature about social capital and online social networks, we develop our conceptual model based on social capital and system acceptance and success theories $[8,9]$ that explains how social capital resources affect the use of social network. In our model, we take into consideration the effects on three variables of social capital resources: social interaction, trust, and knowledge sharing. The concept of social interaction means how users are connected in social relations [20] and the impersonal linkages between users [2]. Some studies have defined social interaction as a link established via reciprocity behavior between users [29]. In addition, trust is pointed to be based on the expectation and respect, honest relationship that people have developed with each other within a community [23]. More specifically, shared knowledge is an organization's most valuable resource for many things such as team goals, team processes, team interaction, etc. $[15,1]$.

We present our conceptual model in Figure 1. According to our model, social capital resources derived from online social networks can influence users' perceived usefulness and finally influence the users' satisfaction.

\section{THEORY FOUNDATION}

\section{Social Capital}

As a set of social capital, resources rooted in social networks have structural, relational and cognitive dimensions [6]. Social capital structural dimension assumes that structural facts as concerning social network system assets and relations, and describing the impersonal configuration of relationships in a community [22]. It deals with the relationships between individuals and their connections with their communities [17]. Social capital relational dimension is related to trust, and trust on social relationship can influence people's behavior [13]. In some studies, trust is one of the important social influence variables, which have been considered highly related to the virtual community [16]. Social capital cognitive dimension provides knowledge sharing ability that helps in knowing the numbers of online topic messages, other people's knowledge and assessment of all information [15]. 


\section{System Success and Acceptance Theories}

According to the D\&M model, user satisfaction measures user opinion of the IS $[8,9]$. TAM model provides an explanation of the determinants of computer acceptance [7]. Perceived usefulness means "the prospective user's subjective probability that using a specific application system will increase his or her job performance within an organizational context," [7: P321]. It has been utilized in many studies to explore user perceptions of system use [24], and has been shown to be a strong determinant of user acceptance $[11,26]$. In the D\&M model, system and information quality are measures to test user satisfaction. However, our study examines social capital variables such as social interaction, trust, and knowledge sharing, which have been considered highly pertinent to the user's satisfaction [28] in an online social network system from a social capital perspective.

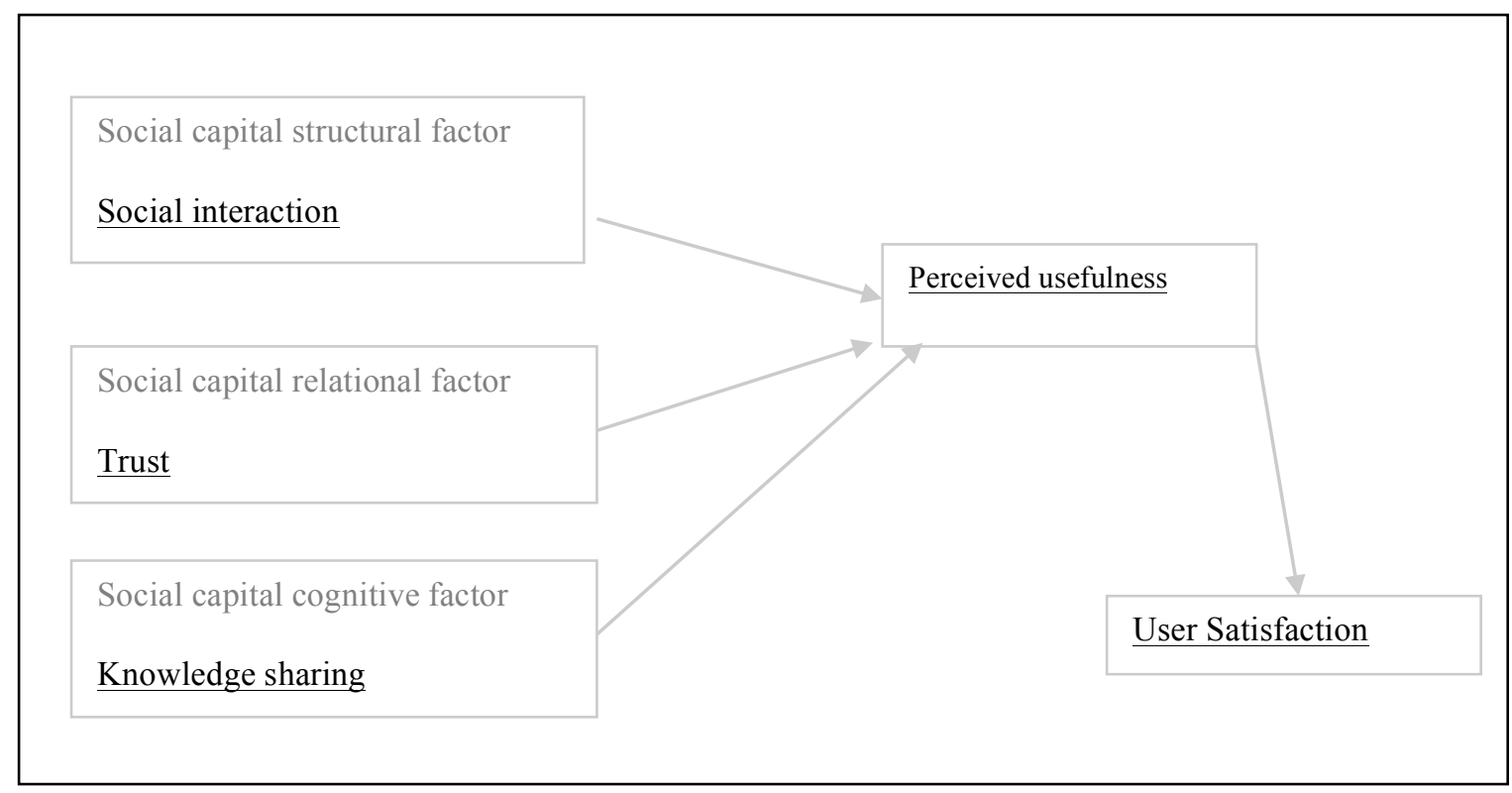

Figure 1. Research Model of Social Capital Effects on an Online Social Network System

\section{RESEARCH MODEL AND HYPOTHESES}

Our independent variables are embedded in the concept of social capital. Social capital has been observed with three different facets [14]. Social capital structural facet is concerned by relationships and interactions of users [5]. Social interaction in a virtual community provides an effective way of outcomes [6]. The more these social interactions build, the greater cooperative and the more effective communications among users are in a community [28]. Social capital relational dimension shows a common concern and mutual trust [12].Trust is defined as agreeableness on and get along with others and by others [15]. Individuals in high degree of trustiness are kind to others, more cooperative, and have effective communication [10]. Trustiness is found to be one of the predictors of social interpersonal relations, adjustment and performance [19].

Cognitive social capital factor relating to knowledge sharing can increase the likelihood of understanding among individuals because it allows them to communicate their knowledge as a result of knowing what they can receive from other people [23]. In addition, how much knowledge is shared and how high quality of knowledge individuals exchange are considered essential for effective outcomes of team work [1]. Consequently, Cognitive social capital dimension provides to identify, analyze, and transform useful information into reusable knowledge which can be used to make decisions [17]. 


\section{Issues in Information Systems \\ Volume 15, Issue I, pp. 217-223, 2014}

We attempt to introduce the concept of social capital effects on the system success and investigate its role in affecting users' satisfaction and perceptions on online social networks. It is noted that high levels of trusting intention likely will be sustained as people interact in cooperative ways [10]. Studies have suggested that frequently visiting a virtual community and interacting during discussions enhances the levels of participation and involvement [5]. In examining the consequences of social capital resources, social capital increases the efficiency of behavior. In particular, researchers have found social capital to encourage cooperative behavior, thereby facilitating the development of new forms of association and innovative organization [6].

According to the above literature reviews, we hypothesize as below (Figure 1):

$\mathrm{H}_{1}$ : Social interaction positively influences perceived usefulness.

$\mathrm{H}_{2}$ : Trust positively influences perceived usefulness.

$\mathrm{H}_{3}$ : Knowledge sharing positively influences perceived usefulness.

$\mathrm{H}_{4}$ : Perceived usefulness positively influences user satisfaction.

\section{RESEARCH METHODOLOGY}

\section{Subjects and Procedures}

The subjects for the experiment were 122 sophomore and junior undergraduate business students enrolled in business information system course. Approximately $38 \%$ of the participants were female. The average age was 21 . The subjects were asked to use the online social networks for their semester group project. They were randomly assigned to the different project groups. Each group had four to five members. The students were given multiple group assignments for the project. All groups had access to the same online social network. On average, it took a group about 7 weeks to complete the project. After they submitted their projects, each student was asked to complete a post session questionnaire.

\section{Measures}

In order to test the proposed hypotheses, we use measurement items found in related studies [6,11, 16, 18, and 28] and modify them for the measures in this research. The scales and the questionnaire for the proposed hypotheses are shown in Appendix A. All measures were taken on seven-point Likert scales, from 1=strongly disagree to $7=$ strongly disagree.

Table1. Convergent Validity and Reliability

\begin{tabular}{|c|c|c|c|}
\hline Construct & Composite reliability & AVE & AVE square root \\
\hline Social interaction & 0.91 & 0.78 & 0.88 \\
\hline Trust & 0.93 & 0.81 & 0.9 \\
\hline Knowledge sharing & 0.87 & 0.75 & 0.87 \\
\hline Satisfaction & 0.92 & 0.8 & 0.89 \\
\hline Perceived usefulness & 0.84 & 0.72 & 0.85 \\
& & & \\
\hline
\end{tabular}

\section{DATA ANALYSIS AND RESULTS}

\section{Measurement Model Analysis}

To analyze the measurement model we first assessed convergent validity by examining average variance extracted (AVE). According to prior research, the perceptual measures should exceed 0.70 . When the composite reliability for each construct is greater than 0.7 , the internal consistency of each construct is good for the model[3]. We found our model results with AVE values exceeding the recommended values of 0.7 (Table 1). 


\section{Issues in Information Systems \\ Volume 15, Issue I, pp. 217-223, 2014}

To evaluate the discriminant validity, the square root of AVE for each construct should be higher than the levels of correlations involving the construct. Table 2 demonstrates the discriminant validity. The square roots of AVE for the constructs (along the table diagonal) are greater than the correlations between two constructs. For example, the square root of AVE for social interaction is 0.88 , greater than the correlations between social interaction and any other construct (the second column table 2).

Table 2. Test of Discriminant Validity: AVE's versus Cross-Construct Squared Correlations

\begin{tabular}{|c|c|c|c|c|c|}
\hline & $\begin{array}{c}\text { Social } \\
\text { Interaction }\end{array}$ & Trust & $\begin{array}{c}\text { Knowledge } \\
\text { Sharing }\end{array}$ & $\begin{array}{c}\text { User } \\
\text { Satisfaction }\end{array}$ & $\begin{array}{c}\text { Perceived } \\
\text { Usefulness }\end{array}$ \\
\hline $\begin{array}{c}\text { Social } \\
\text { Interaction }\end{array}$ & 0.88 & \multicolumn{3}{|c|}{} \\
\hline Trust & 0.36 & 0.90 & \multicolumn{3}{|c|}{} \\
\hline $\begin{array}{c}\text { Knowledge } \\
\text { Sharing }\end{array}$ & 0.24 & 0.32 & 0.87 & \multicolumn{2}{|c|}{} \\
\hline $\begin{array}{c}\text { User } \\
\text { Satisfaction }\end{array}$ & 0.19 & 0.24 & 0.38 & 0.89 & \\
\hline $\begin{array}{c}\text { Perceived } \\
\text { Usefulness }\end{array}$ & 0.13 & 0.17 & 0.15 & 0.16 & 0.85 \\
\hline
\end{tabular}

Table 3. Hypothesis Testing Results

\begin{tabular}{|c|c|c|c|c|}
\hline Hypothesis & Relationship & $\beta$ & P-value & Hypothesis Outcome \\
\hline $\mathrm{H}_{1}$ & $\begin{array}{c}\text { Social interaction->perceived } \\
\text { usefulness }\end{array}$ & 0.05 & 0.15 & Not Supported \\
\hline $\mathrm{H}_{2}$ & Trust -> perceived usefulness & 0.35 & 0.01 & Supported \\
\hline $\mathrm{H}_{3}$ & $\begin{array}{c}\text { Knowledge sharing -> perceived } \\
\text { usefulness }\end{array}$ & 0.11 & 0.03 & Supported \\
\hline $\mathrm{H}_{4}$ & $\begin{array}{c}\text { Perceived usefulness -> user } \\
\text { satisfaction }\end{array}$ & 0.24 & 0.05 & \\
\hline
\end{tabular}

\section{Structural Model Analysis}

The structural model was assessed by conducting a path analysis using PLS. The results of the hypothesis testing are summarized in Table 3. The significance of structural path estimates was computed using the bootstrapping resampling method [26]. Hypothesis $H_{1}$ is not supported due to high $P$ value. But trust $(B=0.35, p=0.01)$ and knowledge sharing $(\beta=0.11, \mathrm{p}=0.03)$ are both found to have a significant influence on perceived usefulness. Furthermore, the relationship between perceived usefulness and user satisfaction is significant $(\beta=0.24, p=0.05)$, so $\mathrm{H}_{2}, \mathrm{H}_{3}$, and $\mathrm{H}_{4}$ are all supported.

H1 is not supported. Social interaction may not positively influences perceived usefulness. Sometimes too much interaction could be negative, only creating some noise. At other times lots of interactions may not be negative but won't solve problems. Sarker et al. [25] also find that too much interaction within a global virtual team is likely to be seen as unproductive or meaningless.

Trust is found to positively impact perceived usefulness of social network systems. A social network system that can enhance mutual trust among its users is more likely to succeed and is more welcomed by the users. This finding is important to both social media such as facebook.com and embedded social platform within enterprise systems. 
Knowledge sharing can have positive effects on perceived usefulness of a social network system. Our finding is in line with our observation from what's going on in the real world. Information and knowledge sharing through news feeding has actually been an important feature of current social media websites. As we expected, perceived usefulness can positively affect user satisfaction.

\section{CONCLUSIONS}

This study has important implications. Today's social networks allow people to share information, pictures, videos, and communicate with each other [21], providing different technology supports to encourage social interaction. In this research, we choose online social network system to test system success using social capital variables. We find that a social network system that enhances trust and knowledge sharing is more likely to succeed. Social interaction is an important feature but its impacts on the system success are not certain as our $\mathrm{H}_{1}$ hypothesis is not supported by the data. Our results imply that social interaction is a necessary feature for a social network system but not sufficient for the social network to succeed. A good social network system should also provide technologies and mechanisms and be designed in such a way, which will create a trustworthy communicative environment and encourage knowledge sharing.

There are several limitations to our study. First, it focuses exclusively on the effect of perceived values. Second, our study only focused on students and sample size is not very big. Third, class project problem solving research may not be generalized to other online social network communities. Moreover, we integrate different aspects of social capital to test users' perceptions on an online social network. The data was collected within a not very long period of time. However, the size and complexity of social structure and time use of social network may make it possible to have some network effects of social capital.

In the future, more extensive data collection efforts are needed to provide deeper analyses. Consistent with the social resource perspective, future research should also explore how other social capital antecedents affect user perceptions, such as social relational choice [17] and social integration. We will also be interested in studying the interrelationships among the three social capital dimensions, and their interrelation effects on social networks as an important focus for future research.

\section{REFERENCES}

1. Bandyopadhyay, S. and Pathak, P. (2007) Knowledge sharing and cooperation in outsourcing projects-a game theoretic analysis. Decision Support Systems, 43(2) 349-358.

2. Burt, R. S. (1992). Structural Holes: The Social Structure of Competition. Cambridge, MA: Harvard University Press.

3. Bock. G.. Zmud. R. W.. Kim. Y.. and Lee. J. (2005) Behavioral intention formation in knowledge sharing: examining the roles of extrinsic motivators, social-psychological forces, and organizational climate. MIS Quarterly, 29(1) 87-111.

4. Cicourel, A. V. (1973). Cognitive Sociology. Harmondsworth, England: Penguin Books.

5. Chow,W. S and Chan, L.S. (2008) Social network, social trust and shared goals in organizational knowledge sharing. Information \& management, 45(7) 458-465.

6. Chang, H. and Chuang,,S. (2011) Social capital and individual motivations on knowledge sharing: participant involvement as a moderator. Information \& Management, 48 (1) 9-18.

7. Davis,F.D. Bagozzi,R.P. , and Warshaw,P.R. (1989) User acceptance of computer technology: a comparison of two theoretical model, Management Science, 35 (8) 982-1003

8. DeLone, W.H. and McLea, E.R. (1992) Information system success: the quest for the dependent variable, Information Systems Research, 3 (1) 60-95.

9. DeLone, W.H and McLean,E.R. (2003) The DeLone and McLean model of information systems success: a ten-year update, Journal of Management Information Systems, 19(4)9-30.

10. Fukuyama, F. (1995) Trust: social virtues and the creation of prosperity. London: Hamish Hamilton.

11. Fuller, R. M., Murthy, U., and Schafer, B. (2010) The effects of data model representation method on task performance, Information \& Management 47 (4)208-218 


\section{Issues in Information Systems \\ Volume 15, Issue I, pp. 217-223, 2014}

12. Gittell, J.H. and Douglass, A. (2012) Relational bureaucracy: structuring reciprocal relationships into roles Academy of Management Review, 37(4)709-733

13. Good, D. (1988) Individuals, interpersonal relations, and trust. In D. Gambetta (Ed.), Trust: Making and breaking cooperative relations: 31-48. New York: Basil Blackwell.

14. Jacobs, J. (1965) The Death and Life of Great American Cities. London: Penguin Books.

15. Kraut, R. and Herbsleb, J. (2007) Team knowledge and coordination in geographically distributed software development, Journal of Management Information Systems, 24(1)135-169.

16. Lin, H. (2008) Determinants of successful virtual communities: Contributions from system characteristics and social factors. Information \& Management, 45(8) 522-527

17. Lin, T. and Huang, C. (2010) Withholding effort in knowledge contribution: the role of social exchange and social cognitive on project teams. Information \& Management 47 (3) 188-196

18. Lu, H., Hsiao, K. (2010) The influence of extro/introversion on the intention to pay for social networking sites. Information \& Management, 47 (3) 150-157

19. Lewicki, R., McAllister, D., and Bies, R. (1998) Trust and distrust: new relationship and realities. Academy of Management Review, 23(3) 438-458.

20. McKnight, DH, Cummings, L., and Chervany, N. (1998) Initial trust formation in new organizational relationships. Academy of Management Review, 23(3) 473-490.

21. Miranda, S., and Saunders, C. (2003) The social construction of meaning: an alternative perspective on information sharing. Information Systems Research. 14(1) 87-106.

22. Nahapiet, J and Ghoshal, S. (1998) Social capital, intellectual capital, and the organizational advantage. Academy of Management Review, 23(2) 242-266.

23. Nov, O., Ye, C. and Kumar, N. (2012) A social capital perspective on meta-knowledge contribution and social computing. Decision Support Systems, 53 (1) 118-126.

24. Shang, R., Chen, Y., and Shen L. (2005) Extrinsic versus intrinsic motivations for consumers to shop on-line. Information \& Management, 42(3) 401-413.

25. Sarker ,S., Ahuja, M., Sarker, S., and Kirkey, S. (2011) The role of communication and trust in global virtual teams: a social network perspective. Journal of Management Information Systems, 28(1) 273-309.

26. Tenenhaus, M., Esposito Vinzj, V., Chatelin Y., and Lauro, C. (2005) PLS path modeling, Computational Statistics \& Data Analysis, 48 (1) 159-205.

27. Taylor, S., and Todd, P. (1995) Understanding information technology usage: A test of competing models. Information Systems Research, 6(2) 144-176.

28. van den Hooff, B. and Huysman, M. (2009) Managing knowledge sharing: emergent and engineering approaches, Information \& Management, 46 (1) 1-8.

29. Wang, J and Chiang, M. (2009) Social interaction and continuance intention in online auctions: a social capital perspective. Decision Support Systems, 47 (4) 466-476. 


\section{Appendix A}

Trust (modified from [16])

1. I feel more confident about discussion skills than the other members.

2. Users know a lot about the discussion subject.

3. Users are concerned about what is important to others.

4 Users will do everything within their capacity to help others.

5: Users try hard to be fair in dealing with each other.

Knowledge Sharing (modified from [28])

I like to be kept fully informed of what other users know.

When I need certain knowledge, I ask other users about it.

I regularly inform other users of what I am working on.

When I have learned something new, I make sure other users learn about it too.

I share information that I acquired, with other users.

I ask other users about their skills when I want to learn particular skills.

I consider it important that other users are aware of what I am working on.

When a user is good at something, I ask him/her to teach me.

Social Interaction (modified from [6])

1: I maintain close social relationships with some members in the online social network.

2: I spend a lot of time interacting with some members in the online social network.

3: I have frequent communication with some members in the online social network.

4: I know some members in the online social network on a personal level.

5: I am not interested in participating in the virtual Community

User satisfaction (modified from [18])

1 I am satisfied with the experience of using social networks

2 I am pleased with the experience of using social networks

3 My decision to use social networks was a wise one.

4 My feeling with using social networks was good

Perceived usefulness (modified from [11])

1. Online social networks allowed me to complete the task more quickly.

2. Online social networks improved my task performance.

3. Online social networks increased my productivity on the task.

4. Online social networks enhanced my effectiveness on the task.

5. Online social networks made it easier to complete the task.

6. Overall, I found the online social networks useful to complete the task. 